\title{
O DISCURSO SOBRE A MINERAÇÃO NA AMAZÔNIA BRASILEIRA: SÍTIO DE EXPLORAÇÃO E FETICHE
}

\section{THE DISCOURSE OF/ON MINING IN THE BRAZILIAN AMAZON: EXPLORATION SITE AND FETISH}

\author{
Maria Virginia Borges Amaral ${ }^{1}$, Gladson Rosas Hauradou ${ }^{2}$
}

\begin{abstract}
RESUMO: O discurso sobre a Amazônia produz um efeito mítico, metaforicamente poético, caracterizado pela beleza natural, apropriado pelo "discurso oficial" do meio ambiente. A região amazônica tem sido apresentada ao mundo como reduto de ecossistemas, de espécies de seres vivos que expressam potencial econômico abundante para atender aos anseios do ardil capitalista contemporâneo. Sobressai na região, ainda, o histórico processo de extração mineral que, atualmente, na condição de commodities (mercadorias), é responsável por grande parte do Produto Interno Bruto (PIB) e da exportação brasileira. Como sítio de Patrimônio Natural da Humanidade, a Amazônia apresenta diversas questões que perpassam as relações de homens e mulheres, cujas vidas são impactadas, no dia a dia, pela presença de agentes exógenos à região. Este estudo volta-se, particularmente, para a Amazônia brasileira. Com o propósito de contribuir com o debate, propomos este estudo sob a ótica da Análise do Discurso para mostrar o fetichismo da exploração no discurso da/sobre a mineração.
\end{abstract}

PALAVRAS-CHAVE: discurso; sítio de exploração; Amazônia; mineração

\begin{abstract}
The discourse on the Amazon produces a mythical, metaphorically poetic effect, characterized by natural beauty, appropriated by the "official discourse" of environmentalism. The Amazon region has been presented to the world as a stronghold of ecosystems, one with species of living beings that expresses abundant economic potential to meet the wishes of the contemporary capitalist ruse. The historic mineral extraction process also stands out in the region, owing to the fact that commodities are responsible for a large part of the Gross Domestic Product (GDP) and for Brazilian exports. As a World Heritage Site, the Amazon presents several issues that permeate the relationships of men and women alike, whose lives are impacted, on a daily basis, by the presence of exogenous agents to the region. This study focuses, in particular, on the Brazilian Amazon. To contribute to the debate, we propose such study from the perspective of the Discourse Analysis in order to show the fetishism of exploration within the discourse oflon mining.
\end{abstract}

\footnotetext{
${ }^{1}$ Doutora em Letras e Linguística pelo PPG em Linguistica e Literatura da UFAL. Docente da Faculdade de Serviço Social (FSSO) e dos PPG Serviço Social e PPG Linguística e Literatura da UFA. Pesquisa com apoio Cnpq.

${ }^{2}$ Doutorando do PPG em Serviço Social da UFAL. Bolsista CAPES/ Fundação de Amparo à Pesquisa do Estado de Alagoas (FAPEAL). Docente do Curso de Serviço Social do Instituto de Ciências Sociais, Educação e Zootecnia da UFAM. Bolsista CAPES
} 
Keywords: discourse; exploration site; Amazon; mining

\section{INTRODUÇ̃̃O}

A formas de exploração da natureza pelo homem e do homem pelo homem por meio do trabalho são renovadas, sofisticadas e aperfeiçoadas hodiernamente na era da mundialização do capital. Mas essa ação exploratória, por estar pautada na ordenança capitalista, implica uma "produção destrutiva", assim como entende Mészáros ao analisar o que ele reconhece ser o "capitalismo avançado". Esse capitalismo "tende a impor à humanidade o mais perverso tipo de existência imediatista" (MÉSZÁROS, 1989, p. 20), determinada pelo "imperativo da lucratividade", condição que qualifica os empreendimentos das empresas como economicamente viáveis. É inegável que esse é um ponto nodal da produção capitalista e, por isso, aplica-se ao processo de exploração da Região Amazônica, sobretudo a brasileira ${ }^{3}$, cuja grandeza não esconde a sua fragilidade, já que, para sobreviver, depende, exclusivamente, de suas propriedades ecossistêmicas subsumidas no ilimitado extrativismo dos seres vivos - a flora e a fauna - e do ambiente composto por elementos físico-químicos - os "famosos minerais".

Neste artigo, analisa-se o discurso sobre a mineração na Amazônia que circula na mídia, tratando de projetos de "empreendedorismo" empresarial, da posição de autoridades governamental e das falas dos amazônidas (povos da Amazônia, incluídos os indígenas). Para introduzir o que se mostrará neste estudo, pode-se antever traços da inquietude de povos da região afetados pelo extrativismo mineral no depoimento de Raimundo Nonato Mendonça, indígena de etnia Mura, cacique da aldeia Ferro Quente, região de Autazes - AM: Nosso município ficou conhecido como a menina dos olhos do governo federal, mas não é por causa da nossa população indígena, que é muito discriminada; é por causa do minério que eles querem levar embora ${ }^{4}$. O cacique é um dos 12 mil indígenas da etnia Mura que vivem na região de Autazes, município do Amazonas, localizado a 113 km da capital, Manaus (BORGES et al, 2020). Mendonça é porta-voz do discurso indígena, não apenas por ser

\footnotetext{
${ }^{3}$ Os estados que compõem a Amazônia Legal são: Acre, Amapá, Amazonas, Mato Grosso, Pará, Rondônia, Roraima, Tocantins e parte do Maranhão (oeste do meridiano de $44^{\circ}$ ). A Amazônia Ocidental é constituída pela área abrangida pelos estados do Amazonas, Acre, Rondônia e Roraima. Já os estados que compõem a Amazônia Oriental são: Pará, Maranhão, Amapá, Tocantins e Mato Grosso. Essa formatação decorreu do dispositivo legal (Lei 1.806 de 06.01.1953) pelo qual a Amazônia Brasileira passou a ser chamada de Amazônia Legal, fruto de um conceito político, e não de um imperativo geográfico. (BRASIL, 2018).

${ }^{4} \mathrm{~A}$ fonte dos depoimentos dos nativos são as reportagens publicadas na mídia. Esse enunciado encontra-se em Borges; Branford; Torres (2020) - Mega-projeto para exploração de potássio no Amazonas gera controvérsias. Disponível em <https://brasil.mongabay.com/2020/01/mega-projeto-para-exploracao-de-potassio-no-amazonas-gera-controversias/>. Acesso em abril de 2020 .
} 
autorizado pela tribo da qual é líder, não somente pela função que exerce na organização social do grupo que representa, mas, sobretudo, por expressar, na posição discursiva que ocupa, a realidade que atormenta e ameaça o seu povo, a partir da expropriação da terra pelo grande capital. $\mathrm{O}$ foco do discurso do governo brasileiro, como mostra a fala do cacique, não é a população indígena, mas o minério, a riqueza da terra, que "eles", o governo e o capitalismo internacional, "querem levar embora". O efeito da expropriação se consolida na sequência discursiva, conclusiva, do discurso indígena no depoimento do cacique: "Para nós, vai ficar apenas o prejuízo, e os políticos não estão do nosso lado".

Ora, parece não haver dúvida que o processo de extrativismo mineral na Amazônia é orquestrado pelos interesses capitalistas enredados pela natureza destrutiva desse sistema de produção. Isso indica que a destruição é planejada, orientada por projetos definidos para operar em um local e data pré-determinados, como é o caso do projeto de exploração do potássio em Autazes - AM, iniciado em 2013 pela Potássio do Brasil, uma empresa multinacional, subsidiária do banco comercial canadense Forbes \& Manhattan ${ }^{5}$. A implantação de um projeto de exploração de minério dessa proporção afeta a comunidade e a sua história; os marcadores temporais - o ontem, o hoje e o depois - são ativados na condição de vida na região. A inserção de um projeto de extrativismo mineral em uma localidade marca um acontecimento - assim como entende Pêcheux (1990, p. 17): "um ponto de encontro de uma atualidade e uma memória" - que tem no discurso - uma particularidade de expressão da realidade social (AMARAL, 2016) - uma maneira de explicitar a contextura de tal "empreendimento".

Provavelmente, seja desnecessária uma análise muito acurada da ação do homem sobre a natureza nos últimos tempos para se ver que o processo predatório, inerente ao modus operandi capitalista, tem avançado em escala planetária e atinge inúmeros redutos de "sociobiodiversidades" na região da Amazônia até então ilesos à rentabilidade orgânica da lógica de mercado (HAURADOU; AMARAL, 2019). É possível que algumas áreas da Amazônia desconheçam o movimento de expropriação decorrentes das intervenções capitalistas, já que a realidade daquele local é tomada por relações sociais peculiares. Muitos amazônidas são imbuídos de uma cosmovisão alheia ao modo de ser capitalista; são, assim como entende Ranciaro (2014, p. 78), populações tradicionais que vivem em espaços ditos

\footnotetext{
5 Borges; Branford; Torres (2020), em matéria intitulada "Mega-projeto para exploração de potássio no Amazonas gera controvérsias", publicada, originalmente, na agência de notícias Mongabay (https://brasil.mongabay.com), em 07 de janeiro de 2020, lembram que "o projeto de exploração mineral está envolto numa contenda judicial. A empresa Potássio do Brasil, responsável pelo empreendimento, conseguiu obter a licença para fazer a prospecção do minério em Autazes sem realizar a consulta prévia, livre e informada ao povo Mura, como determina a Convenção 169 da Organização Internacional do Trabalho (OIT)".
} 
tradicionais ${ }^{6}$, e "resguardam, por isso mesmo, seus traços peculiares, tecidos por uma 'teia de significados' que confere a esses povos o seu caráter de particularidades simbólicas emaranhadas nessa mesma teia de significações".

A Amazônia é tida como um dos maiores e mais complexos ecossistemas do mundo. Localizada na bacia hidrográfica do rio Amazonas, tem uma superfície total de pouco mais de 7 milhões de $\mathrm{km}^{2}$, o que corresponde a cerca de $40 \%$ do continente sul-americano (TULIO NETO, 2010), uma região formada por oito países (Brasil, Bolívia, Peru, Equador, Colômbia, Venezuela, Guiana e Suriname, esses últimos unidos ao complexo amazônico mais pela similaridade vegetal e climática e menos pela unidade hidrográfica). Esta é a chamada "Amazônia Continental” (BRASIL, 2018). A região é definida como um "complexo ecossistema", um campo rico de possibilidades e potencialidades naturais no qual, ainda, persistem inúmeras formas de apropriação da natureza em favor do capital e em detrimento dos povos (e da vida) nela existentes.

Por todas as características naturais que dão à Amazônia o atributo de sítio sociobiodiverso e, portanto, um sítio de exploração em potencial, uma fonte de valores de uso na qual coexistem relações sociais anteriores à forma de ser burguesa. A região lida, cotidianamente, com os efeitos da presença de agentes externos e exploradores da sua riqueza. $\mathrm{Na}$ condição de fonte dos valores de uso - de fonte de riqueza -, o "complexo de ecossistemas" amazônico tem se revelado historicamente como espaço profícuo e contínuo de expropriação, num processo ditado por empreendimento nacional e internacional que afeta, sobremaneira, as condições de vida dos povos amazônidas. Tais intervenções tendem a promover mudanças substantivas no ambiente e nas relações sociais da região.

As relações sociais próprias das "populações tradicionais" daquela região em muito se distanciam da sociabilidade burguesa ocidental subsumida ao domínio do capital ao longo da história. Ora, a lógica expansionista do capital encontra solo fértil na região da Amazônia, sobretudo devido ao caráter pluridimensional das relações sociais e de produção que ali se encontram, muitas vezes revelando-se como contraponto ao capitalismo. As questões da Amazônia são inúmeras e diversificadas, perpassam as relações de homens e mulheres, cujas vidas são impactadas, no dia a dia, pela presença de agentes exógenos à região. A exogenia

\footnotetext{
${ }^{6}$ Para Freitas (2009, p. 22; grifos nossos): “As sociedades tradicionais da região exercitaram, por milênios, a convivência pluricultural interétnica, e plurinacional em sociedades de abundância e de ocupabilidade plena. Pode ser dito que a colonização e o desenvolvimento do capitalismo na Amazônia criaram os problemas regionais, o subdesenvolvimento econômico e sociocultural, inventaram a pobreza e a dependência, além de instituírem a desigualdade estrutural e federativa, de 'classes' e de povos". Freitas (Idem) destaca, ainda, que "os homens da Amazônia pré-colonial não eram só caçadores e coletores. Eram artesãos, navegadores e possuidores de um nível técnico capaz de dar conta das necessidades de reprodução de grandes contingentes humanos e do domínio cultural sobre os territórios litorâneos, centrais e ribeirinhos do espaço físico".
} 
avança cada vez mais em áreas amazônicas devido ao investimento devassador do capital, confundindo-se, às vezes, com uma ação moderna-conservadora, uma "modernização conservadora" cuja riqueza natural contraria a dureza da realidade social. É assim que Teixeira (1998, p. 103) descreve o paradoxo da Amazônia e por isso a torna : “[...] uma região em cujos municípios, principalmente naqueles dos grandes projetos, desfilam crianças que na rua imploram por um pouco de comida, adultos coletando alimento no lixo, [...] índios se prostituindo nos bordéis improvisados [...]". À essa realidade, soma-se a "violência sexual infantil nas suas distintas manifestações”, observam Hauradou; Amaral (2019, p. 406).

Por tudo isso, é importante conhecer os efeitos de exploração do minério, ou efeitos do "empreendimento extrativista", como os "empreendedores" costumam se referir à ação de exploração da natureza, produzidos no discurso sobre a mineração. As materialidades discursivas - textos em forma de depoimentos que constituem o corpus da investigação foram abstraídas de matérias jornalísticas divulgadas em sites da internet de natureza pública. Tais materialidades serviram aos propósitos da análise, fornecendo elementos discursivos para que se pudesse conhecer e compreender o processo de mineração na Região Amazônica e seus efeitos destrutivos. O conhecimento dessas questões é uma exigência para que o Brasil e, particularmente, os amazônidas, possam encontrar estratégias de mobilização e organização que subsidiem respostas às demandas coletivas da região. Com esse estudo, realizado sob a ótica da Análise do Discurso, espera-se contribuir com o debate acerca de problemáticas concernentes a práticas extrativistas da Região Amazônica, ao se desvelar no discurso os efeitos de exploração e de fetiche.

\section{Efeitos de sentidos no discurso sobre a mineração na Amazônia}

A Amazônia é considerada pela comunidade científica mundial, representada pela Organização das Nações Unidas para a Educação, a Ciência e a Cultura (UNESCO), uma região (área ou sítio) de inigualável importância para a humanidade, por isso foi nomeada, no início deste século XXI, como "Patrimônio da Humanidade", devendo ser cuidada e preservada pelo país (ou países) que a abriga. Hoje, está entre as Sete Maravilhas Naturais do Mundo, classificada em primeiro lugar no Grupo E (categoria para as florestas, parques nacionais e reservas naturais). Isso é para dizer como a Amazônia tem sido apresentada ao mundo: um bioma ${ }^{7}$ de grande diversidade natural; um reduto de ecossistemas que expressam

\footnotetext{
${ }^{7}$ O Brasil é formado por seis biomas de características distintas: Amazônia, Caatinga, Cerrado, Mata Atlântica, Pampa e Pantanal (BRASIL - MMA, 2020). 
potencial econômico abundante. Mas, o que parece ser uma fonte de beleza e benefícios para a humanidade, acaba por se transformar em um sítio de exploração "para atender aos anseios do ardil capitalista contemporâneo" (HAURADOU; AMARAL, 2019, p.403).

Não é à toa que designamos, metaforicamente, a Amazônia como um sítio de exploração. Essa denominação por nós atribuída à Região Amazônica sustenta-se em aspectos de natureza geográfica e discursiva, considerando, contudo, a imbricação desses dois campos - o geográfico e o discursivo - no processo da análise do discurso do qual trata este artigo. No campo geográfico, com predominância do sentido geopolítico, Amazônia é referida em muitas ocorrências discursivas como uma região, uma área ou um sítio. É o que se pode ver quando a Unidade de Conservação Socio Ambiental no Brasil do Instituto Socioambiental $\left(\right.$ ISA, 2020) ${ }^{8}$, por ocasião da declaração da Amazônia Central como Patrimônio Natural da Humanidade, refere-se à Amazônia: "Novo sítio inclui 4 unidades de conservação: Jaú, Anavilhanas, Amanã e Mamirauá". Ainda no campo geográfico, com prevalência do sentido fitogeográfico, a expressão sítio diz respeito à realidade ecossistêmica: uma área geográfica que representa o maior bioma desse país - um território de 4.196 .943 milhões de km2 (IBGE, 2004), em que crescem 2.500 espécies de árvores (ou um terço de toda a madeira tropical do mundo) e 30 mil espécies de plantas, das 100 mil da América do Sul, como revela o Ministério do Meio Ambiente - MMA (BRASIL - MMA, 2020). Esses elementos de imbricação geográfica implicam o espaço físico, mas também discursivo, em que são produzidos os discursos sobre a Amazônia, entre eles o discurso sobre a mineração.

$\mathrm{O}$ aspecto discursivo da noção de sítio remete ao conceito de sítio de significância, desenvolvido por Orlandi (1998, p. 13) no qual Amaral (2016) se apoia para compreender a função da Formação Discursiva no processo de produção de sentidos no discurso. Amaral (idem, p. 46) adota a expressão "sítio de significação" para referir a esse espaço discursivo de produção de sentidos, “espaço de regulação e de confronto de muitos dizeres, que tanto podem apontar para uma mesma formação ideológica como para o confronto entre duas formações [Formação Ideológica do Capital e Formação Ideológica do Trabalho]”. Desse entendimento conceitual decorre a expressão sítio de exploração que cunhamos, tanto para referir, metaforicamente ${ }^{9}$, à região - ou área - da Amazônia como um campo de confronto

\footnotetext{
${ }^{8}$ O Instituto Socioambiental (ISA) é “uma organização da sociedade civil brasileira, sem fins lucrativos, fundada em 1994, para propor soluções de forma integrada a questões sociais e ambientais com foco central na defesa de bens e direitos sociais, coletivos e difusos relativos ao meio ambiente, ao patrimônio cultural, aos direitos humanos e dos povos" (ISA, 2020).

${ }^{9}$ Revisitamos AMARAL (2016, p. 89-90) para a compreensão da noção de metáfora no campo da Análise do Discurso. Diz ela: “[...] Se a metáfora, como diz Pêcheux (1988, p. 263), 'é sempre determinada pelo interdiscurso', haveremos de concordar que na metáfora há um sentido que já está dado, que é repetível, que permite a interpretação. Mas esse sentido não é entendido apenas como o sentido literal da palavra; esse sentido é convocado no processo de produção da metáfora para ser
} 
entre o capital e o trabalho, como para fazer jus ao conceito "sítio de significância" ou "sítio de significação" da teoria da Análise do Discurso e mediar a análise, considerando, inclusive, a contradição que sustenta toda e qualquer expressão referencial ${ }^{10}$.

Dito isto, pode-se, então, tratar da contradição sob a qual se assenta a expressão sítio de exploração. Ao mesmo tempo em que tem como referente uma área geográfica que representa o maior bioma do Brasil, favorável à extração de enorme quantidade de matériaprima para ser transformada em produção beneficiadora das necessidades dos homens, a expressão sítio de exploração traduz os efeitos destrutivos dessa ação. Por um lado, o discurso sobre a Amazônia produz um efeito mítico, metaforicamente poético, caracterizado pela beleza natural, apropriado pelo "discurso oficial"11 do meio ambiente: "um verde e vasto mundo de águas e florestas, onde as copas de árvores imensas escondem o úmido nascimento, reprodução e morte de mais de um terço das espécies que vivem sobre a Terra" (BRASIL MMA, 2020); por outro lado, são conhecidos os conflitos pela terra - insurgidos por trabalhadores diversos destituídos de propriedades e dos meios de produção, munidos somente de sua força de trabalho. Esses conflitos, ora velados, ora visivelmente combatidos com brutal violência pelo Estado ou por segmentos da sociedade civil (latifundiários, fazendeiros, grileiros etc.), expressam a contradição do modo de produção capitalista sob a qual se assenta a luta das classes fundamentais ${ }^{12}$ tradicionalmente reconhecida, na acepção marxista, como a burguesa (detentora da propriedade) e o proletariado (que apenas possui a força de trabalho $)^{13}$. Hoje, essas classes são comumente referidas como os capitalistas e os trabalhadores.

As particularidades dos conflitos na região amazônica revelam o agravamento dessa questão. Cabe lembrar as declarações da Conferência Nacional dos Bispos do Brasil (CNBB)

\footnotetext{
deslocado, para ser ressignificado na situação imediata ou circunstância da enunciação e provocar novos efeitos de sentido. Daí a verdade da metáfora ser contextual, como vimos em Mészáros (1993)".

${ }^{10}$ Amaral (2016, p. 76) considera que, "a noção de "expressão referencial" serve como um recurso linguístico usado pelo locutor para se referir (ou não referir explicitamente, como ocorre no processo de "silenciamento") a um sujeito, uma coisa, ou a um acontecimento". Nesse sentido, retomamos o termo expressão referencial por considerar que atende aos propósitos deste estudo; por compreendê-lo um recurso discursivo necessário à explicitação de um acontecimento discursivo, marcado pelo interdiscurso no complexo da formação discursiva.

${ }^{11}$ Entendemos, como Silva (2015), que o discurso oficial é relativo ao discurso documental jurídico. Neste estudo, toma-se como materialidades do discurso oficial os documentos emanados de instituições públicas, especificamente do Ministério do Meio Ambiente, ou documentos apropriados e autorizados por elas quando formulados por instâncias com competência para tratar sobre o tema, como é o caso das empresas ou organizações públicas nacionais e multinacionais.

${ }^{12}$ Amaral (2019, p. 86), em nota, lembra, numa acepção marxiana, que as classe sociais na sociedade capitalista, devido à propriedade privada, restringiram-se em duas: "O resultado final, portanto, é a abolição da distinção entre capitalista e grande proprietário de maneira que, ao todo, há apenas duas classes de população, a classe trabalhadora e a classe capitalista" (MARX, 1989, 150).

${ }^{13}$ Para Marx (1989, p. 16-17) “somente o proletariado é uma classe realmente revolucionária”. A organização política dessa classe é muitas vezes rompida pela concorrência entre os operários. Disso decorre que os operários não formam uma classe em si, mas são constitutivos da classe proletária.
} 
acerca das inúmeras manifestações que conformam a ação destrutiva do capitalismo não só na Amazônia, mas em várias unidades federativas do Brasil, na década de 1980:

\begin{abstract}
As forças policiais e privadas aparecem conjuntamente nas soluções de conflitos agrários. A Conferência Nacional dos Bispos do Brasil - CNBB, em 1980, fez a seguinte declaração: 'Em quase todas as unidades da Federação, sob formas distintas, surgem conflitos entre, de um lado, grandes empresas nacionais e multinacionais, grileiros e fazendeiros e, de outro, posseiros e índios. Violências de toda a ordem se cometem contra esses últimos para expulsá-los da terra. Nessas violências, já se comprovou amplamente, estão envolvidos desde jagunços e pistoleiros profissionais, até forças policiais, oficiais de Justiça e juízes. Não raro, observa-se a anomalia gravíssima de composição de forças de jagunços e policiais para executar sentenças de despejo'. As denúncias são intermináveis, aparecendo em cena os grandes proprietários, juízes, pistoleiros e policiais. (BARREIRAS, $1999 \mathrm{p}$. 139).
\end{abstract}

As denúncias sobre os conflitos são contínuas e "intermináveis"; fazem surgir na cena da violência "os grandes proprietários, juízes, pistoleiros e policiais", como observa Barreira (1999). $\mathrm{Na}$ (des)ordem desses acontecimentos, a história registra o massacre em Eldorado do Carajás $^{14}$, em 1996 e, mais recentemente, no ano de 2017, em Pau D’arco ${ }^{15}$, no Pará. Esses ataques aos trabalhadores é uma das faces do sítio de exploração, que decorre da “incontrolabilidade da natureza destrutiva do capital”, assim como diz Mészáros (1989, p. 22), quando lembra que "o capital não trata valor-de-uso (que corresponde diretamente à necessidade) e valor-de-troca meramente como dimensões separadas, mas de uma maneira que subordina radicalmente o primeiro ao último"16.

A região da Amazônia é atualmente responsável por grande parte da extração mineral no Brasil; "atingiu em 2017 a participação de 8\% do total do PIB brasileiro - um avanço em relação aos 5,8\% registrados 20 anos antes e aos 7,2\% de 10 anos atrás” (TREVIZAN, 2018). As commodities $^{17}$ (mercadorias) são responsáveis por esse avanço; em 2014, representavam

\footnotetext{
${ }^{14}$ Cabe observar, ainda a partir de Barreira (1999, p. 137), o que foi e o que implicou esse acontecimento: “[...] grave conflito que ocorreu entre as forças de segurança do Estado do Pará (Polícia Militar) e trabalhadores rurais. O campo brasileiro é novamente palco de um cenário importante ocorrido no dia 17 de abril de 1996, quando o governador do Pará 'mandou a polícia militar desocupar uma estrada no sul do seu Estado. Saldo da operação de trânsito rodoviário: uma carnificina com duas dezenas de sem-terra mortos e 51 feridos. Os homens e as mulheres atacados na floresta, que deixaram sangue e pedaços de cérebro espalhados pelo chão e pela relva, são esses brasileiros chamados de sem-terra, cidadãos que andam descalços, têm roupas sujas de barro e só costumam ser notícia na forma de cadáver" (Veja, 24/04/96). Este acontecimento foi nomeado como o "massacre de Eldorado dos Carajás".

${ }^{15}$ Cabe lembrar do "[...] massacre que vitimou dez trabalhadores rurais em Pau D’Arco, no município de Redenção, sudeste do Pará [...]. O crime aconteceu na madrugada do dia 24 de maio de 2017. Dezenove policiais foram investigados pelas mortes; 13 deles indiciados e atualmente presos, mas os mandantes da chacina não chegaram a ser identificados". (PORTAL AMAZÔNIA, 2018; grifos do autor).

${ }^{16}$ Importa observar que é na mercadoria que Marx (1988) identifica a dupla realidade do trabalho na produção capitalista: "trabalho concreto" - que se realiza no valor de uso - e "trabalho abstrato" - que se realiza no valor de troca. Diz ele: "Para criar mercadoria, é mister não só produzir valor de uso, mas produzi-lo para outros, dar origem a valor de uso social” (p. 48), isto é, dar origem a valor de troca. Esse processo é silenciado na forma mercadoria do trabalho; nessa forma do trabalho, não se percebe imediatamente o processo destrutivo da produção capitalista.

${ }^{17}$ Castro (2018, p. 1) esclarece que "A palavra inglesa 'commodity' significa simplesmente mercadoria. Mas no mercado o termo se refere a produto básico, em estado bruto ou com baixo grau de transformação. São mercadorias com pouco valor agregado e quase sem diferenciação - que podem, portanto, ser negociadas globalmente sob uma mesma categoria. Minério de ferro, madeira, carne e frango 'in natura' e petróleo são algumas das mais comercializadas".
} 
6,8\% do PIB brasileiro, como lembra Castro (2018) a partir dos dados da Conferência das Nações Unidas sobre Comércio e Desenvolvimento, o que equivale a $65 \%$ do valor das exportações brasileiras. A força das commodities no Brasil leva Hauradou e Amaral (2019, p. 403) a indicarem que "[...] essa mercadoria tem sido extraída de várias regiões do Brasil e de outros países da América Latina; mas, particularmente, na Amazônia brasileira, sua extração plasma um quadro específico, que se realiza num contexto de modos de vida diferenciados, de relações sociais (de produção) também diferenciadas."

Ora, ao analisar a mercadoria, Marx (1988, p. 41) destaca que: "A riqueza das sociedades onde rege a produção capitalista configura-se em 'imensa configuração de mercadorias' e a mercadoria isoladamente considerada é a forma elementar dessa riqueza". E acrescenta: “A mercadoria é, antes de mais nada, um objeto externo, uma coisa, que por suas propriedades, satisfaz necessidades humanas seja qual for a natureza, a origem delas, provenham do estômago ou da fantasia" (Idem). Podem-se considerar as commodities, então, nessa concepção marxiana de mercadoria - mercadorias "extraídas" da natureza mediante "trabalho humano" para atender a determinadas necessidades humanas. A extração de propriedades da natureza para responder às necessidades dos homens é um dos elementos constitutivos da discursividade da expressão metafórica sítio de exploração e implica a transformação da "natureza amazônica" em mercadoria dotada de valores de uso e de troca, enquanto expropria do amazônida a sua condição de existir e reproduzir a vida no seu habitat.

A mineração na Amazônia, como todo processo de extração e exploração da natureza na sociedade capitalista, não tem apreço pelo homem. Veja-se o caso do "Mega-projeto" para a extração do Potássio ao qual nos referimos no início deste artigo. A Agência Nacional de Mineração (ANM) autorizou, em 2013, a Potássio do Brasil a iniciar suas atividades de pesquisa na Região da Amazônia, dentro de uma área da comunidade indígena TI Jauary, escavando, justamente, um cemitério sagrado para aquela comunidade. Borges; Branford; Torres (2020) relatam na matéria jornalística já citada a inquietude e a reação dos povos indígenas para cessar as escavações. A falta de apreço pelo homem amazônico por parte das empresas mineradoras é visível na fala da indígena tuxaua da aldeia Sampaio, Gilmara Lelis: Quando as lideranças perceberam, eles já estavam extraindo esse material sem nos consultar (BORGES; BRANFORD; TORRES, 2020). As lideranças, uma referência à representação do amazônida, são logradas por "eles", os exploradores da terra que agem sem consultar os habitantes. Esse enunciado revela o processo de expropriação e violação do direito do indígena - "sem nos consultar” é a expressão que remete à denúncia de tal violação. 
Para lutar contra a invasão da mineração em suas terras, o povo indígena apela para o sentido de coletivo sob o qual se assenta a organização em aldeias, visto que não conta com a proteção jurídica que, em princípio, seria o papel do Estado por meio dos órgãos competentes. É o que se pode ver na sequência discursiva seguinte, apreendida também na fala da indígena Gilmara: Nós somos um povo só. Mexeu com uma aldeia tá (sic) mexendo com todos nós, porque não vai afetar só uma aldeia, mas sim todos nós. Nós lutamos pelo um coletivo (sic) (BORGES; BRANFORD; TORRES, 2020). Muitos dos sujeitos amazônicos são afetados pela presença desses agentes exógenos à região - as empresas e exploradores dos bens naturais do sítio. Muitos, sobretudo os indígenas, lutam pela sobrevivência/subsistência quase isoladamente; às vezes dispõem de organizações coletivas tradicionalmente reconhecidas e institucionalizadas juridicamente, como é o caso de algumas associações. Ademais, a fragilidade do processo organizativo dos amazônidas, não apenas indígenas, deve-se ao caráter multifacetado das populações da região, de sua particularidade geográfica expressa na sinuosidade dos rios e das áreas com florestas de terra firme e de várzea (GAMA; et alii, 2005) que imprimem limitações ao fluxo (trânsito) intercomunitário, questão que vem sendo dirimida com a presença incipiente das novas tecnologias e das mídias digitais. Acerca do caráter multifacetado, como bem reconhece Freitas (2009, p. 23-24):

\begin{abstract}
As populações contemporâneas da Amazônia são compostas de grupos sociais urbanos e rurais heterogêneos do ponto de vista da situação econômica; de sociedades e comunidades indígenas de distintos e diversos modos de adaptação e articulação histórico-cultural; de grupos isolados remanescentes de fricção interétnicas e de arranjos próprios de sobrevivência com a sociedade nacional; e, ainda, de grupos e contingentes populacionais deslocados para a região por mecanismos governamentais, privados e confessionais e por migrações internas e externas, independentes ou promovidas por fluxos de exploração econômica ou reajustes institucionais na Amazônia.
\end{abstract}

Em decorrência do desprezo pelo homem amazônico por parte das empresas mineradoras, nesse sítio de exploração têm-se inúmeros efeitos destrutivos. Muitos estudos sobre as irregularidades e riscos da mineração no Amazonas têm sido realizados como sinal de alerta. Borges; Branford; Torres, (2020) remete à Fernanda Bragato, autora de um dos estudos sobre os impactos da mineração na Amazônia, para anunciar que desde a “implantação do canteiro de obras da empresa já ocorre uma série de impactos associados, como doenças infectocontagiosas, além de problemas sociais, como aumento no consumo de drogas, nos índices de violência, na prostituição e nos casos de exploração sexual infantil”. Então, é disso que estamos falando quando caracterizamos a região da Amazônia como um sítio de exploração. Nesse sítio, os diversos impactos destrutivos estão associados e se expressam em uma rede de sentidos: o adoecimento, a dependência de drogas, a prostituição, 
a exploração sexual infantil - que ecoam no discurso da exploração do trabalho pelo capital. Disto decorre a marginalização de homens e mulheres que, sob a condição de "apêndice do mercado" (POLANYI, 2000), são atingidos pelas consequências deletérias (refrações ou reflexos) do processo de exploração, que neles recaem de forma brutal.

\section{O fetichismo da exploração da/na Amazônia}

As commodities de minério, tendo as empresas de mineração na região amazônica brasileira à frente, sob o aval do Estado brasileiro, apesar de desempenharem um papel expressivo na produção nacional, legam às sociedades amazônicas o ônus inerente à rentabilidade capitalista; atendem a propósitos alheios aos reais interesses e necessidades dos sujeitos locais, engendrando um quadro histórico de desigualdades. Para os sujeitos amazônicos sobram as consequências deletérias da forma de ser do capital e o acirramento da desigualdade local em suas muitas dimensões (HAURADOU; AMARAL, 2019). Essa é a realidade sob o efeito de fetichização da exploração do minério.

Um fetiche, sabe-se, pode ser entendido como uma fantasia ou como um feitiço. Pensamos, a partir de Marx (1988, p. 79), quando trata sobre "o fetichismo da mercadoria: seu segredo", que a palavra exploração parece, à primeira vista, uma expressão perfeitamente compreensível, assim como a mercadoria. Mas, analisando-a, veremos que é uma expressão "fantasmagórica" que omite as relações sociais que a definem; é complexa e passível de muitos sentidos a depender do ambiente discursivo no qual se encontra. No campo da investigação, exploração remete ao conhecimento da área geográfica, de pessoas por meio de suas histórias de vida, de documentos ou de materiais bibliográficos que subsidiarão a interpretação do objeto da pesquisa por parte do pesquisador; é a chamada "pesquisa exploratória", uma das fases necessárias e indispensáveis da investigação. Esse procedimento investigativo também é prática que precede a ação para a transformação de uma determinada realidade.

A exploração, no sentido de investigação que remete ao conhecimento da região, está incorporada ao discurso sobre a mineração desde a realidade que precede todo o processo de intervenção de empresas mineradoras na Amazônia até sua implantação. A mineradora Potássio do Brasil, da qual trata a matéria referida no início desse artigo, fez uma investigação exploratória para conhecer a localidade, e o que seria necessário para a realização do seu projeto extrativista. A partir daí, anunciou o "empreendimento" em Autazes-AM em setembro de 2010, que previa um investimento de 2,5 milhões de dólares para implantar poços de 
extração mineral, reformar a estrada, o porto no rio Madeira e uma linha de transmissão de energia (BORGES; BRANFORD; TORRES, 2020). O planejamento para explorar terras na região incorpora uma espécie de acordo entre os "empreendedores" e os amazônidas, simulando efeitos de benefício para ambos.

Pode-se observar esse movimento discursivo na fala do porta-voz do discurso oficial, o prefeito do município de Autazes-AM, Anderson Cavalcante: $O$ que eles anunciam pra gente (sic) são 1,5 mil empregos diretos no pico da implantação, chegando a 5 mil empregos indiretos (BORGES; BRANFORD; TORRES, 2020). Enquanto enaltece o benefício do extrativismo mineral devido ao caráter produtivo que reverterá em prol da coletividade, o discurso sobre a mineração, representado pelo governo municipal, silencia o caráter destrutivo da prática de exploração do minério. O efeito destrutivo está silenciado na memória discursiva $^{18}$ do acontecimento que se pode perceber na fala do amazônidas Aldinelson Pavão, tuxaua de Urucurituba: Não mencionaram nenhum impacto negativo, só positivo. Então, muita gente acredita que vai ser bom, né? (BORGES; BRANFORD; TORRES, 2020). Aldinelson refere-se à audiência feita por representantes da empresa mineradora para apresentar os estudos exploratórios e o planejamento de exploração do minério à comunidade; seria, pois, o acontecimento durante o qual "Não mencionaram" o lado negativo da mineração e "muita gente acredita que vai ser bom".

A realidade social foi se modificando e os amazônidas sentiram "o impacto" das mudanças. Na posição de porta-voz do seu povo Adinelson, anuncia: Fomos para a justiça e mostramos para eles que existe índio e que nós temos direito na terra que é nossa. Nós que moramos aqui. Eu já tenho 47 anos, nasci e me criei aqui, meus pais e meus avós também. Então eu acredito que não é a Potássio que vem de lá dizer que a terra não é nossa (BORGES; BRANFORD; TORRES, 2020). Percebe-se a relação entre o processo de exploração da terra e o de expropriação de direitos - existe índio e que nós temos direito na terra que é nossa. Embora o discurso sobre a mineração, divulgado pelos empreendedores e governantes, atribua à exploração o sentido de extração/produção para a qual justifica a "ocupação da terra", o que ocorre de fato, como bem anuncia o depoimento do líder comunitário, é um processo de expropriação, de tomada, de desapropriação de um bem, assim

\footnotetext{
${ }^{18}$ Retomamos, aqui, a nota 5 de Amaral (2019, p. 87) acerca de memória discursiva: "Noção de memória discursiva está ancorada em Pêcheux (1999, p. 52), que revela a sua complexidade, considerando-a para além daquilo '[...] que face a um texto que surge como acontecimento a ler, vem restabelecer os 'implícitos' (quer dizer, mais tecnicamente, os préconstruídos, elementos citados e relatados, discursos transversos etc.) de que sua leitura necessita [...]'. Pêcheux questiona: 'A questão é, saber onde residem esses famosos implícitos [...]: estão eles disponíveis na memória discursiva como um fundo de gaveta, um registro oculto?". Pêcheux (p. 56) indica que há “o outro interno em toda memória" que é, ao seu ver, "a marca do real histórico como remissão ao outro exterior, [...] ao real histórico como causa do fato de que nenhuma memória pode ser um frasco sem exterior" (p. 56).
} 
como entende Amaral (2019). Expropriar indica o sentido de indenizar ou transferir, compulsoriamente, uma propriedade para o poder público, "mediante prévia indenização do expropriado". Mas, o discurso sobre a mineração anunciado pelo líder comunitário não indica nenhum processo de indenização legalizada; expressa, contudo, uma prática de destituição de direito e de invasão, de tomada da posse da terra - não é a Potássio que vem de lá dizer que a terra não é nossa -, sobressaindo-se, no enunciado, o sentido de desapropriação da terra que se fortalece no sítio da exploração.

Ora, o que se pode ver no processo de mineração na região da Amazônia é o ato de expropriação realizado pelo capitalismo, respaldado pela administração pública, para privar uma pessoa da titularidade da terra por meio de uma indenização fictícia com o intuito de reparar o dano. "Fictícia" porque, mesmo utilizando o "discurso oficial", o ato de expropriação cria a ilusão de um ganho coletivo; o dano é omitido no discurso legislado de bem comum.

O discurso da expropriação ganha sentido no sítio de exploração onde o "discurso transverso" (interdiscurso) ${ }^{19}$ da exploração se sustenta e manifesta a natureza contraditória desse acontecimento discursivo. Amaral (2019, p. 89-90), ao identificar o ponto de deriva que revela a contradição do discurso, diz que, "ao afirmar", o discurso "nega a si e ao outro do discurso, nega a sua memória discursiva, produzindo [...] efeito de desmemória". Explica a noção de efeito de desmemória a partir de Pêcheux (1990, p. 54): "há o outro na história correspondente a esse outro próprio ao linguareiro discursivo, que aí pode haver ligação, identificação ou transferência". Com esse entendimento, pode-se dizer que sítio de exploração, o espaço constituído pelos sentidos produzidos no discurso sobre a mineração, é o ponto de deriva revelador da contradição do discurso da exploração transverso no discurso sobre a mineração. Nesse sítio, é permitido ao discurso sobre a mineração, representado pelas empresas, produzir efeitos de crescimento e desenvolvimento da região Amazônica, enquanto os amazônidas anunciam, nesse mesmo sítio, os efeitos destrutivos dessa intervenção extrativista. Disso decorre que o discurso sobre a mineração põe uma tensão entre o sentido de extração/produção e o sentido da exploração/destruição; enquanto apresenta a ação extrativista como beneficiadora da população, como produtora de mercadoria e meios de

\footnotetext{
19 Assim como diz Pêcheux (1988, ibidem, p. 167), acerca do interdiscurso como discurso transverso: "o interdiscurso enquanto discurso transverso atravessa e põe em conexão entre si elementos discursivos constituídos pelo interdiscurso enquanto pré-construído, que fornece, por assim dizer, a matéria-prima na qual o sujeito se constitui como 'sujeito falante', com a formação discursiva que o assujeita". No caso em estudo, a formação discursiva que assujeita está representada como um sítio de exploração.
} 
sobrevivência para o sujeito nativo da região, cria a ilusão de mais trabalho para empregar as pessoas e dar-lhes condições de vida.

O sentido de extração/produção é condição de convencimento da benesse, antecipa e inscreve no funcionamento discursivo o sentido da ocupação do espaço pelo capital na região da Amazônia. Ora, é interessante ressaltar o dizer marxiano para o qual "o capital é a força econômica da sociedade burguesa que tudo domina” (MARX, 1983, p. 225), o que implica reconhecer, no funcionamento do discurso sobre a mineração, o poder social do capital, que conduz à junção, mas, também, à dissolução das coisas e das pessoas nesta forma de ser da sociedade capitalista. O discurso sobre a mineração na área da Amazônia produz efeitos de igualdade de oportunidade para todos; simula efeitos de fortalecimento das relações sociais e silencia a dissolução dessas relações com a agudização das desigualdades em suas múltiplas dimensões. O sentido de produção mineral na modalidade commodities produz evidências de geração de riqueza para atender as demandas da população, quando, na verdade, gera um distanciamento cada vez maior entre os interesses do capital e os da população, submetendo-a à lógica expansionista da produção destrutiva do capital, sob o "imperativo da lucratividade" (MÉSZÁROS, 1989, p 27).

\section{CONSIDERAÇÕES FINAIS}

Por fim, para que se possa pensar que o discurso sobre a mineração na Amazônia, mas também em muitas outras regiões do Brasil, renova-se e impulsiona a prática devastadora do homem sobre a natureza, cabe dizer que o avanço do capital, com sua natureza destrutiva, está incontrolável. Para Teixeira (2008, p. 147), “a industrialização, encravada na Amazônia, não consegue mudar o caráter de atividade produtiva não-soberana para o país e não altera a condição da região como fonte de saque", o que significa dizer que a aquisição de certificados de patrimônio e os projetos de empresas empreendedoras, comemorados pelas autoridades da região e do país, não resultam em avanços reais para a população.

A presença e o avanço do capital na região da Amazônia implicam o aniquilamento do ecossistema e da vida dos nativos nas distintas localidades. Cabe, pois, lembrar que, de certa maneira, a Amazônia resiste à homogeneização econômica, cultural e política que os “empreendedores” querem impor à região (TEIXEIRA, 1998). A resistência ante as investidas do capital na região expressa-se nas formas sociais de organização dos amazônidas, sobretudo dos indígenas, como se pode ver nos depoimentos dos líderes ou representantes comunitários conformados a uma "vontade política" - um posicionamento político que se gesta no cotidiano das "população afetadas pelos projetos de desenvolvimento" (HAURADOU; 
AMARAL 2018, p. 1080) na região. Ao se organizarem e ao se fazerem representar pelas suas lideranças, os amazônidas expressam essa vontade política "em favor do bem comum", contrariando o "discurso oficial" que subverte o efeito da mineração: à frente das sequelas da exploração é subsumida a valorização dos recursos minerais para agregar ao "patrimônio natural" e transformá-lo em mercadoria a ser vendida ao capital internacional. O avanço do capital na região amazônica tem ocorrido sob a tutela do Estado brasileiro, porta-voz do "discurso oficial", numa relação que expropria, anula e dissolve relações seculares, sobrepondo um modo de ser alheio à cultura e aos costumes locais.

Contudo, o efeito destrutivo do sítio de exploração na Amazônia, em que se processa o discurso sobre a mineração, impede que o extrativismo proposto por "grandes projetos" atenda às necessidades dos amazônidas que são absorvidos pelo fetichismo de liberdade produzido na vida cotidiana, enquanto é silenciado no discurso os efeitos da exploração das mineradoras. É o que revela a fala de Josequias Antônio da Silva, líder comunitário da vila Elesbão, às margens do Amazonas: Estão morrendo crianças e os próprios adultos. Mas ninguém vem informar a gente de nada. A população continua nadando no rio e comendo camarão (SAKAMOTO, 2001). O fato é que a burguesia comemora o aumento da sua riqueza, enquanto a população que trabalha para reproduzir a sua vida e a dos seus familiares adoece e morre contaminada pelos resíduos da mineração nos rios ${ }^{20}$ e em todo o sítio de exploração da Amazônia brasileira.

\section{REFERÊNCIAS}

AMARAL. M.V.B. O discurso do trabalho e suas múltiplas expressões materiais e ideológicas. Entremeios [Revista de Estudos do Discurso, ISSN 2179-3514, on-line, www.entremeios.inf.br], Seção Estudos, Programa de Pós-Graduação em Ciências da Linguagem (PPGCL), Universidade do Vale do Sapucaí (UNIVÁS), Pouso Alegre (MG), vol. 20, Especial, Dossiê "Língua, discurso e trabalho na contemporaneidade", p. 85-100, dez. 2019.

$<$ http://dx.doi.org/10.20337/ISSN21793514revistaENTREMEIOSvol20pagina85a100> AMARAL. M.V.B. Discurso e relações de trabalho. Maceió: Edufal, 2005, 2016.

BARREIRA, César. Crônica de um massacre anunciado: Eldorado dos Carajás. In: São Paulo Perspec. vol.13 no.4 São Paulo Oct./Dec. 1999. Disponível em <https://www.scielo.br/scielo.php?script=sci_arttext\&pid=S0102-88391999000400015> Acesso em 20 de maio 2020.

BORGES, Thais; BRANFORD Sue; TORRES Maurício. Mega-projeto para exploração de potássio no Amazonas gera controvérsias. Disponível em

\footnotetext{
${ }^{20}$ A Indústria e Comércio de Minérios S.A. (ICOMI) foi acusada em 2001, pelo governo do estado do Amapá, de ter contaminado a região do porto de Santana, próximo da capital Macapá, com arsênio - substância altamente tóxica que pode provocar câncer e até a morte. O desastre ambiental atingiu a vila Elesbão, uma comunidade de pescadores que vive sobre palafitas às margens do rio Amazonas (SAKAMOTO, 2001).
} 
$<$ https://brasil.mongabay.com/2020/01/mega-projeto-para-exploracao-de-potassio-noamazonas-gera-controversias/> Acesso em abril de 2020.

BRASIL. Ministério da Integração Nacional. Superintendência do Desenvolvimento da Amazônia - SUDAM. Legislação da Amazônia. Disponível em <http://www.sudam.gov.br/index.php/prda/58-acesso-a-informacao/86-legislacao-daamazonia>. Acesso em 05 abr. 2018.

BRASIL. Ministério do Meio Ambiente - MMA <https://www.mma.gov.br/biomas/amaz\%C3\%B4nia> Acesso em 19 de maio de 2020.

CASTRO, José Roberto. As commodities e seu impacto na economia do Brasil. Disponível em: <https://www.nexojornal.com.br/explicado>. Acesso em: 03 mai. 2018.

FREITAS, Marilene Corrêa da Silva. Os amazônidas contam a sua história: territórios, povos, populações. In: SCHERER, Elenise \& OLIVEIRA, José Aldemir de (Orgs.). Amazônia: territórios, povos tradicionais e ambiente. Manaus: Editora da Universidade Federal do Amazonas, 2009

GAMA, João Ricardo Vasconcellos; SOUZA, Agostinho Lopes de; MARTINS, Sebastião Venâncio Martins; SOUZA, Ricardo de Souza. Comparação entre florestas de várzea e de terra firme do Estado do Pará. In: Rev. Árvore vol.29 no.4 Viçosa July/Aug. 2005. http://dx.doi.org/10.1590/S0100-67622005000400013

HAURADOU, G. R.; AMARAL, M. B. Sujeitos coletivos e vontade coletiva na Amazônia: uma aproximação do pensamento de Gramsci. In: Brazilian Applied Science Review 2 (3), 1075-1086, 2018

A Reiteração do conservadorismo e as possibilidades de enfrentamento no Serviço Social. Anais do XVI Encontro Nacional de Pesquisadores em Serviço Social, v. 16 n. 1, 2018. Disponível

em <http://www.periodicos.ufes.br/?journal=abepss\&page=article\&op=view\&path[]=26252>. Acesso em 15 maio 2020.

Mineração na Amazônia Brasileira: aspectos da presença e avanço do capital na região. In: Revista de Políticas Públicas. vol. 23, n. 1, 2019 Disponível em 〈http://www.periodicoseletronicos.ufma.br/index.php/rppublica/index > Acesso em 12 de maio de 2020.

INSTITUTO BRASILEIRO DE GEOGRAFIA E ESTATISITCA [IBGE]. Disponível em www.ibge.gov.br; 〈https://agenciadenoticias.ibge.gov.br/agencia-noticias>. Acesso em 15 de maio de 2020.

INSTITUTO SOCIOAMBIENTAL - ISA <https://www.socioambiental.org/pt-br/o-isa> Acesso em 22 de maio de 2020

MÉSZÁROS, Iatvan. Produção Destrutiva e Estado Capitalista. São Paulo: Ensaio, 1989.

MÉSZÁROS, Iatvan. Filosofia ideologia e Ciencia social: ensaios de negação e afirmação São Paulo: Ensaio, 1993.

MARX, Karl. O Capital. Livro I, vol. I. 12 ${ }^{\mathrm{a}}$ ed. Rio de Janeiro: Bertrand Brasil, 1988

MARX, Karl. O Capital. Livro I, vol. II. 12a ed. Rio de Janeiro: Bertrand Brasil, 1988

MARX, Karl. Contribuição à crítica da economia política. São Paulo: Martins Fontes, 1983.

ORLANDI, Eni Pulcinelli. A leitura proposta e os leitores possíveis. In: Eni Orlandi (org.). A leitura e os leitores. Campinas: Pontes, 1998.

PÊCHEUX, M. O discurso: estrutura ou acontecimento. Campinas: Pontes, 1990.

PÊCHEUX M.; FUCHS C. A propósito da análise automática do discurso: atualização e perspectivas. Em: GADET, F.; HAK, T. (Orgs). Por uma análise automática do discurso. Uma introdução à obra de Michel Pêcheux. $2^{\mathrm{a}}$ ed. Campinas: Editora da Unicamp, 1993. PÊCHEUX, M. (1975). Semântica e Discurso: uma crítica a afirmação do óbvio. Campinas: Editora da Unicamp, 1988 e 1997. 
Papel da memória. In: ACHARD, Pierre...et alii. Papel da Memória. Campinas. SP: Pontes 1999.

PINTO, Lúcio Flávio. A utopia amazônida. Disponível em: <http://amazoniareal.com.br/autopia-amazonida/>. Acesso em 04 ago. 2018.

POLANYI, Karl. A grande transformação. Rio de Janeiro: Elsevier, 2000.

PORTAL AMAZÔNIA. Um ano depois, massacre de Pau D'arco, no Pará, tem 13 indiciados. Disponível em: <http://portalamazonia.com/noticias/um-ano-depois-massacre-depau-darco-no-para-tem-13-indiciados>. Acesso em 27 mai. 2018.

RANCIARO, Maria Magela Mafra de Andrade. Formação histórica e tradições socioculturais vivenciadas em povoados rurais amazônicos. In: CHAVES, Maria do Perpétuo Socorro Rodrigues; SANTIAGO, Jozane Lima. Inovação, Desenvolvimento e Sustentabilidade na Amazônia. Manaus: EDUA, 2014.

SAKAMOTO, Leonardo. Triste herança. Repórter Brasil. São Paulo, jan. 2001. Disponível em: 〈http://www.reporterbrasil.com.br/exibe >. Acesso em: 22 maio de 2020.

SILVA, Sóstenes Eriscon Vicente. Agronegócio e Agricultura Familiar: a desfaçatez do Estado e a insustentabilidade do discurso do capital. Maceió: Edufal, 2015.

TEIXEIRA, Joaquina Barata. A assistência social na Amazônia. In: Sev. Soc. Ano XIX, nº 56, março, 1998.

Meio Ambiente, Amazônia e Serviço Social. Revista em Pauta, Faculdade de Serviço Social da Universidade do Estado do Rio de Janeiro. n. 21, 2008.

TREVIZAN, Karina. Economia da Amazônia brasileira cresce mais que a média do país, mas rendimento na região continua menor. Disponível em $<$ https://g1.globo.com/economia/noticia/2018/08/30/economia-da-amazonia-brasileira>. Acesso em 20 de maio de 2020.

TULIO NETO, Petrônio de. Soberania e ingerência na Amazônia brasileira. Rio de Janeiro: Centro Edelstein de Pesquisa Social, 2010, 82p. ISBN 978-85-7982-047-2. Available from SciELO Books. Disponível em <http://books.scielo.org >. Acesso em 02 jun. 2018.

Recebido em 29/05/2020. Aceito em 17/09/2020. 